\section{Planting Date Affects Total Glucosinolate Concentrations in Six Commercial Cabbage Cultivars}

\author{
Theodore J.K. Radovich, ${ }^{1}$ Matthew D. Kleinhenz, ${ }^{2}$ John G. Streeter, ${ }^{3}$ A. \\ Raymond Miller, ${ }^{3}$ and Joseph C. Scheerens ${ }^{4}$ \\ Department of Horticulture and Crop Science, The Ohio State University, Ohio \\ Agricultural Research and Development Center (OARDC), 1680 Madison \\ Avenue, Wooster, Ohio 44691-4096
}

Additional index words. flavor, pungency, sensory quality, stress, temperature

\begin{abstract}
Glucosinolates are secondary plant metabolites derived from amino acids and they influence human health, pest populations and crop flavor. Our primary objective was to determine the independent and interactive effects of planting date (PD) and cultivar (C) on total glucosinolate concentrations in cabbage, in part to help develop management systems that optimize them. A second objective was to explore the reported link between total glucosinolate concentrations and pungency in fresh cabbage. Six commercial fresh market cabbage cultivars were planted in May and June 2001 and 2002 at the Ohio Agricultural Research and Development Center (OARDC) Vegetable Crops Research Branch in Fremont, Ohio. Total glucosinolate concentrations in horticulturally mature heads were determined using a glucose evolution procedure. In 2001, 12 to 14 experienced panelists also scored sample pungency. Total glucosinolate concentrations were significantly affected by PD and $\mathrm{C}$, but the $\mathbf{P D} \times \mathbf{C}$ interaction was not significant. Mean glucosinolate concentrations were greater in May- than June-planted cabbage in both years. Cultivar ranking with regard to glucosinolate concentrations was similar between planting dates in both years. 'Cheers' had the highest mean glucosinolate concentrations $\left(23.1\right.$ and $29.5 \mathrm{mmol} \cdot \mathrm{kg}^{-1} \mathrm{dry}$ weight in 2001 and 2002, respectively) and 'Solid Blue 790' the lowest $\left(17.1\right.$ and $19.7 \mathrm{mmol} \cdot \mathrm{kg}^{-1} \mathrm{dry}$ weight in 2001 and 2002, respectively). In 2001, panelists generally scored cultivars highest in glucosinolates as more pungent than cultivars lowest in glucosinolates. These data suggest that planting date and cultivar effects on total glucosinolate concentrations in cabbage are largely independent. Climatic data suggest that higher air temperatures during head development of May- compared to June-planted cabbage induced plant stress and resulted in higher glucosinolate concentrations in May-planted cabbage.
\end{abstract}

Glucosinolates are plant-mobile, sulfurand glucose-containing compounds found in several families of the order Capperales, including the Brassicacea (Chen and Andreasson, 2001). These anionic secondary products are derived from amino acids and possess little or no biological activity. However, the enzyme myrosinase (EC 3.2.1.147) catalyses the hydrolytic cleavage of the glucose moiety and, accompanied by the spontaneous release of sulfate from the unstable intermediate, produces a biologically active aglucon whose structure depends on the conditions

Received for publication 30 July 2003. Accepted for publication 23 June 2004. Manuscript number HCS04-02. Salaries and research support provided in part by State and Federal funds appropriated to the Ohio Agricultural Research and Development Center, The Ohio State University. Work also supported in part by grants from the Ohio Vegetable and Small Fruit Research and Development Program. The important contributions of Brenda Schult, Sonia Walker, Aida Sanchez-Vela, Nate Honeck, Stahn Gahn, Matt Hofelich and staff of the OARDC Vegetable Crops Research Branch in Fremont, Ohio are gratefully acknowledged. Use of trade names does not imply endorsement of the products named nor criticism of similar ones not named.

${ }^{1}$ Graduate research associate

${ }^{2}$ Associate professor and corresponding author.

${ }^{3}$ Professor.

${ }^{4}$ Associate professor. et al. 1997; Verhoeven et al., 1997), while minimizing levels is expected to increase flavor acceptance by consumers of fresh vegetables (Chin et al., 1996; van Doorn et al., 1998). The influence of glucosinolates on crop and product quality is particularly important to growers, processors and researchers as glucosinolates are responsible for a range of flavor attributes, including pungency or hotness, bitterness, and sulfurous aroma (MacLeod, 1976; van Doorn et al., 1998). Glucosinolates, in particular, may contribute to the unacceptable pungency of coleslaw and other fresh shredded cabbage products (Ball et al., 1999; Yano et al., 1987). Therefore, horticultural manipulation of glucosinolate concentrations in cabbage may be worthwhile (MacLeod and Nussbaum, 1977; Rosa et al., 1997). For example, cabbage growers alter planting dates within a season according to weather, labor and equipment availability, or market issues. These decisions, in turn, may affect crop quality and marketability due to climate changes throughout the season (Kleinhenz and Wszelaki, 2003).

Planting date and cultivar selection are thought to affect concentrations of glucosinolates and their hydrolysis products in cabbage. Bible et al. (1980), Kushad et al. (1999) and Van Etten et al. $(1976 ; 1980)$ described large differences in glucosinolates or their metabolites among cabbage cultivars. In a survey of 22 genotypes, Van Etten et al. (1976) reported a difference of $>400 \%$ between cultivars with the highest and lowest total glucosinolate concentrations. Environmental effects on glucosinolate levels may also be large. Rosa et al. (1996) reported higher glucosinolate concentrations in a single cabbage cultivar of the Capitata group when planted in March compared to August in Portugal, and attributed the lower concentrations in August-planted cabbage to lower air temperatures later in plant development. Planting date had a similar effect on head concentrations of thiocyanate (a goitrogenic glucosinolate metabolite) in two cabbage cultivars in Quebec (Bible et al., 1980). Contrary to Rosa et al. (1996), Bible et al. (1980) attributed higher thiocyanate concentrations in June- compared to Mayplanted cabbage to low soil moisture during development of June-planted cabbage. In Great Britain, MacLeod and Nussbaum (1977) reported lower isothiocyanate concentrations in two cabbage cultivars planted and harvested late in the season, compared to earlier plantings. However, no explanation for the effect was offered. Overall, investigations of the planting date effect on cabbage glucosinolate concentrations are few, include none in the U.S., and use a limited number of current commercial cultivars. Planting date and cultivar are reported to influence important cabbage head traits (Kleinhenz and Wszelaki, 2003; Wszelaki and Kleinhenz, 2003), yet their effect on total glucosinolate concentrations are understudied. Therefore, our primary objective was to examine the independent and interactive effects of planting date and cultivar on total glucosinolate concentrations in cabbage. A second objective was to explore the reported link between total glucosinolate concentrations and pungency in cabbage.

\section{Materials and Methods}

Plot establishment, maintenance and harvest. Hardened 'Blue Dynasty', 'Bronco', 'Cheers', 'HMX 0228', 'Matsumo', and 'Solid Blue 790' seedlings with two to four true leaves were planted to the field 10 May and 
20 June 2001 and 28 May and 25 June 2002 at the OARDC Vegetable Crops Research Branch in Fremont, Ohio (latitude $40^{\circ} 47^{\prime} \mathrm{N}$, longitude $81^{\circ} 55^{\prime} \mathrm{W}$ ). Two-row plots were planted with a cone-type two-row transplanter (Holland Transplanter, Holland, Mich.). Plots were arranged in a randomized complete block design with four replications. Each replication contained both planting dates and all cultivars. Rows were $4.6 \mathrm{~m}$ long with $76 \mathrm{~cm}$ between rows and $28 \mathrm{~cm}$ between transplants. Soil type in each year was a Kibbie fine sandy loam (fine illitic mesic Mollic Ochraqualf). Preplant fertilizer applications were based on soil tests and local practices. For the 2001 planting, $31.4 \mathrm{~kg} \cdot \mathrm{ha}^{-1}$ of $\mathrm{P}(0 \mathrm{~N}-20.1 \mathrm{P}-0 \mathrm{~K})$ and 256.4 $\mathrm{kg} \cdot \mathrm{ha}^{-1}$ of $\mathrm{K}(0 \mathrm{~N}-0 \mathrm{P}-49.8 \mathrm{~K})$ were applied to the field on October 23, 2000 and $78 \mathrm{~kg} \cdot \mathrm{ha}^{-1}$ of $\mathrm{N}(45 \mathrm{~N}-0 \mathrm{P}-0 \mathrm{~K})$ was applied on 1 May 2001 and incorporated just before planting. For the 2002 planting, $140 \mathrm{~kg} \cdot \mathrm{ha}^{-1}$ of N (45N-0P-0K), $73.4 \mathrm{~kg} \cdot \mathrm{ha}^{-1}$ of $\mathrm{P}(0 \mathrm{~N}-20.1 \mathrm{P}-0 \mathrm{~K})$ and 325.4 $\mathrm{kg} \cdot \mathrm{ha}^{-1}$ of $\mathrm{K}(\mathrm{ON}-0 \mathrm{P}-49.8 \mathrm{~K})$ were applied to the field on 5 May 2002 and incorporated just before planting. Each transplant was provided with about $150 \mathrm{~mL}$ of a dilute nutrient solution [(129 and $184 \mathrm{mg} \cdot \mathrm{L}^{-1}$ of $\mathrm{N}$ and $\mathrm{P}$, respectively $(10 \mathrm{~N}-14.8 \mathrm{P}-0 \mathrm{~K})]$ at planting. Standard pest management strategies, based on scouting, thresholds, and application of labeled pesticides, were used. Plots received $25 \mathrm{~mm}$ of irrigation on 28 June and 16 July 2001 and $38 \mathrm{~mm}$ on 15 July 2002. Temperature data were collected hourly on-site by the OARDC Weather System (The Ohio State University, 2003).

Harvest and physical trait data collection. Plots were examined two to three times per week beginning $55 \mathrm{~d}$ after transplanting to assess harvest readiness. Harvest dates were selected based on estimated days to maturity from the seed source and visual examination of heads, following the practice of commercial growers in the area and that used in related research (Kleinhenz and Wszelaki, 2003; Wszelaki and Kleinhenz, 2003). All heads were collected from the center $3 \mathrm{~m}$ of both rows in each plot and scored as marketable or unmarketable as previously reported (Kleinhenz and Wszelaki, 2003). Heads were then randomly selected from the marketable group and trimmed (four wrapper leaves removed) before further evaluation. In 2001, individual weights were taken on five heads using an electronic scale (FV-60KWP; A and D Co., Ltd Tokyo, Japan or CW11-2EO; OHAUS, N.J.). Polar and equatorial head diameters were also measured. Three additional heads from each replication were selected for glucosinolate analysis and stored at $7{ }^{\circ} \mathrm{C}$ for $<48 \mathrm{~h}$ before processing. Also, in 2001, two heads from each replication were retained for pungency evaluation and stored 20 to $40 \mathrm{~d}$ until sensory panels were convened. In 2002, head weight and diameter were recorded on the three heads selected for glucosinolate analysis.

Pungency evaluation. In 2001, 12 (Juneplanted) or 14 (May-planted) untrained panelists familiar with the sensory evaluation process evaluated shredded samples of each cultivar for the attribute hot as previously re- ported (Radovich et al., 2003). Samples were homogenized composites of eight heads (two from each of the four field replications), with panelists serving as replications in the analysis of the sensory evaluation data (Radovich et al., 2003). The attribute hot was described to panelists as the irritation (pungency) perceived in the mouth and nasal passages when consuming horseradish, a sensation familiar to all evaluators. Evaluations were made relative to a reference, on a continuous line scale, anchored on the left by much less hot and on the right by much more hot and centered with the reference (Radovich et al., 2003). Marks on the scale were converted to numerical values, and cultivar means generated with SAS for Windows v.8 (Statistical Analysis System, Cary, N.C.). Data for May- and June-planted cabbage were analyzed separately due to differences in panel composition.

Glucosinolate analysis. A $1.5-\mathrm{cm}$-thick longitudinal slice was taken from the center of each head and the core removed. The slice was halved longitudinally; one half was immediately frozen in liquid nitrogen and stored at $-20{ }^{\circ} \mathrm{C}$ until lyophilized. Glucosinolates were extracted after the procedure of Rosa and Rodriques (1998). Ground, freeze-dried tissue (200 mg) was heated in $5 \mathrm{~mL}$ of $90 \%$ aqueous methanol in a capped test tube at $70{ }^{\circ} \mathrm{C}$ for 15 minutes, then vacuum filtered through coarse, qualitative filter paper $(5.5 \mathrm{~cm}$, Fisher Scientific, Pittsburgh, Pa.). Sinigrin (2-propenyl glucosinolate; $6 \mu \mathrm{mol}$, Sigma Chemical Co., St. Louis, Mo.) was added as an internal standard to duplicate tubes of about $25 \%$ of the samples to estimate recovery $($ mean $=82 \%$, standard error $=1.5 \%, \mathrm{~N}=71$ ) and confirm equality in recovery rates among treatments (data not shown). The residue was reheated twice in 5 $\mathrm{ml}$ of $70 \%$ aqueous methanol at $70{ }^{\circ} \mathrm{C}$ for 3 min and filtrates were collected in $500-\mathrm{mL}$
Erlenmeyer flasks. The combined filtrate was evaporated under vacuum (Rotavapor VE 50 GD; Rinco Instrument Co. Inc., Greenville, Ill.) and the residue redissolved in $10 \mathrm{~mL}$ of $70 \%$ methanol. The extract was then centrifuged at 27,200 $g_{\mathrm{n}}$ for $10 \mathrm{~min}$. The supernatant was collected in $10-\mathrm{mL}$ vials and stored at $<0{ }^{\circ} \mathrm{C}$ until analysis.

The glucose evolution procedure of Heaney and Fenwick (1981) was used to quantify total glucosinolate concentrations in samples. Pasteur pipettes $(14.6 \mathrm{~cm})$ plugged with glass wool were filled with $0.5 \mathrm{~mL}$ of Sephadex A-25 resin (Sigma Chemical Co., St. Louis, Mo.) previously swollen and degassed in 0.02 $\mathrm{M}$ pyridine acetic acid buffer, $\mathrm{pH}$ 5.5. Resin was rinsed twice with $2 \mathrm{~mL}$ distilled water, draining between rinses. Cabbage extract (1 $\mathrm{mL}$ ) was added to columns and allowed to drain. Column were then washed with 0.3 $\mathrm{mL}$ of distilled water, allowed to drain, and washed again with $2 \mathrm{~mL}$ distilled water. Columns were then washed twice with $0.5 \mathrm{~mL}$ of $0.02 \mathrm{M}$ pyridine acetic acid buffer. Glass

Table 1. Analysis of variance for the influence of year, planting date, and cultivar on total glucosinolate concentrations in six cultivars of fresh-market cabbage planted in May and June 2001 and 2002 at the OARDC Vegetable Crops Research Branch in Fremont, Ohio.

\begin{tabular}{lcc}
\hline Source & df & $\begin{array}{c}\text { Total } \\
\text { glucosinolate } \\
\text { concentration }\end{array}$ \\
\hline Year (Y) & 1 & $* * *$ \\
Planting date (PD) & 1 & $* * *$ \\
Cultivar (C) & 5 & $* * *$ \\
Y $\times$ PD & 1 & $* *$ \\
Y $\times \mathrm{C}$ & 5 & $*$ \\
$\mathrm{PD} \times \mathrm{C}$ & 5 & $\mathrm{NS}$ \\
$\mathrm{Y} \times \mathrm{PD} \times \mathrm{C}$ & 5 & $\mathrm{NS}$ \\
\hline NS,***,***Nonsignificant or significant at $P \leq 0.05,0.01$ \\
or 0.001, respectively.
\end{tabular}

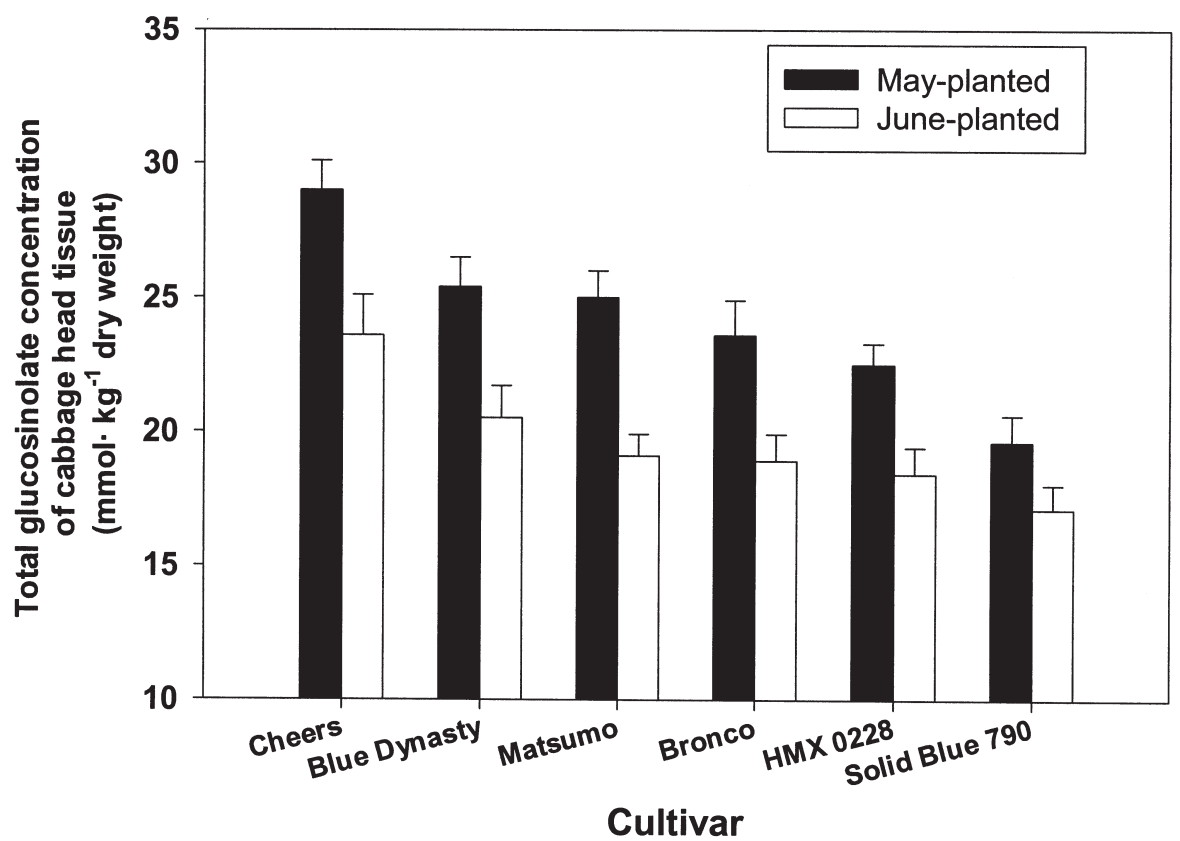

Fig. 1. Mean total glucosinolate concentrations in head tissue of six cabbage cultivars planted in May and June of 2001 and 2002 at the OARDC Vegetable Crops Research Branch in Fremont, Ohio. Values are means of three subsamples from each of four replications across years. Error bars are standard mean errors. 

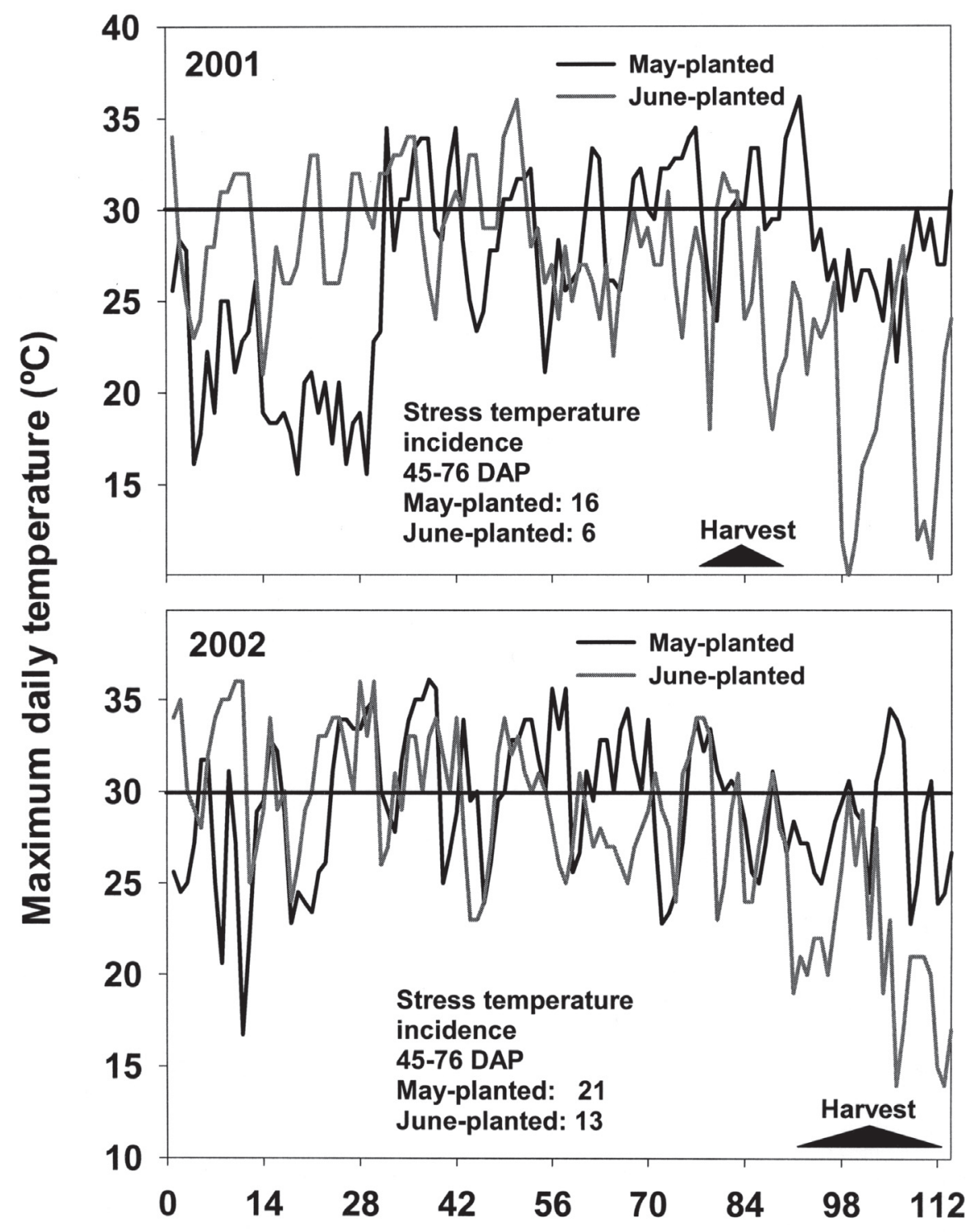

Days after planting

Fig. 2. Maximum daily air temperatures during cabbage development in May and June of 2001 and 2002 at the OARDC Vegetable Crops Research Branch in Fremont, Ohio. Within years, the difference between planting dates in days to harvest (DTH) was $<7 \mathrm{~d}$ for all cultivars. The base of each solid triangle indicates the harvest period for both planting dates within years.

collection vials $(10 \mathrm{~mL})$ were placed under the column and $0.8 \mathrm{U}$ of thioglucosidase (Sigma Chemical Co., St. Louis, Mo.) in 0.25 mL 0.02 $\mathrm{M}$ pyridine acetic acid, $\mathrm{pH} 5.5$ was added to the columns. Columns were left at ambient conditions (about $25^{\circ} \mathrm{C}$ ) for $16 \mathrm{~h}$, then eluted with two volumes of $0.5 \mathrm{~mL}$ distilled water. The glucose concentration of the eluate was determined colorimetrically at $340 \mathrm{~nm}$ using glucose (HK) assay kits (Sigma Chemical Co.) and a Beckman spectrophotometer (model DU 640; Beckman Instruments Inc., Fullerton, Calif.). Glucose values were converted to equimolar amounts of glucosinolate (the molecular weight of the internal standard sinigrin, 415.5, was used) and corrected for internal standard recovery. Data were analyzed with the General Linear Model and Correlation procedures of SAS for Windows v.8 (Statistical Analysis System, Cary, N.C.). were harvested 25 to 30 July 2001 (76 to 81 DAP) and 26 Aug. to 12 Sept. 2002 (90 to 107 DAP); June-planted heads were harvested 7 to 13 Sept. 2001 (79 to 85 DAP) and 18 Sept. to 17 Oct. 2002 ( 85 to 114 DAP). Mean head weight and diameter were lower in Maycompared to June planted cabbage in both years (data not shown). A greater incidence of stress temperatures in 2002 retarded head development compared to 2001, and differences among cultivars in the developmental response to stress temperatures contributed to the extended harvest period in 2002 relative to 2001 (Radovich et al., 2004).

Mean cultivar glucosinolate concentrations ranged between 17.1 and $29.0 \mathrm{mmol} \cdot \mathrm{kg}^{-1}$ dry weight (Fig. 1). 'Cheers' and 'Solid Blue 790' contained the highest and lowest concentration of glucosinolates, respectively. 'Cheers' was also perceived to be the most pungent cultivar in evaluations of May- and June-planted cabbage (Radovich et al., 2003). Cultivar pungency scores were significantly (alpha $=0.10$ ) correlated with mean glucosinolate concentrations in the evaluation of June-planted cabbage only (Fig. 3). The difference in glucosinolate concentrations between 'Cheers' and 'Solid Blue 790' was greater in $2002\left(9.8 \mathrm{mmol} \cdot \mathrm{kg}^{-1}\right.$ dry weight $)$ than in $2001\left(6.0 \mathrm{mmol} \cdot \mathrm{kg}^{-1} \mathrm{dry}\right.$ weight) (data not shown). Although mean total glucosinolate concentrations for all cultivars were greater in 2002 than 2001, cultivars varied in their magnitude of increase from 2001 (data not shown). Therefore, the range in glucosinolate concentrations among cultivars was greater in 2002 than 2001 .

\section{Discussion}

The importance of glucosinolates in crop sensory quality, human health and plant defense make them a primary target for horticultural manipulation during production. Therefore, it is important to note that both planting date and cultivar influenced total glucosinolate levels in the commercial genotypes employed here (Table 1). More importantly, the PD $\times$ $C$ interaction was not significant and cultivar rank with regard to glucosinolate concentration was very similar between years and planting dates. Therefore, it appears that PD and Cacted independently in influencing glucosinolate concentrations in this study. The absence of a significant $\mathrm{PD} \times \mathrm{C}$ effect on glucosinolate concentrations also simplifies interpretation of the planting date effect.

Temperatures of $30^{\circ} \mathrm{C}$ or greater are considered supra-optimal for cabbage (Rubatzky and Yamaguchi, 1997). These temperatures were recorded more frequently during head development in May- than June-planted plots and, overall, more often in 2002 than 2001 (Fig. 2). Perhaps as a result, mean glucosinolate concentrations were greater in 2002 compared to 2001 and the PD effect was less pronounced in 2002 than 2001 (data not shown). Glucosinolates are thought to act in plant defense, with environmentally induced increases in glucosinolate concentrations regarded as a plant stress response (Rask et al., 2000; Siemens and Mitchell-Olds, 1996). Recent work 


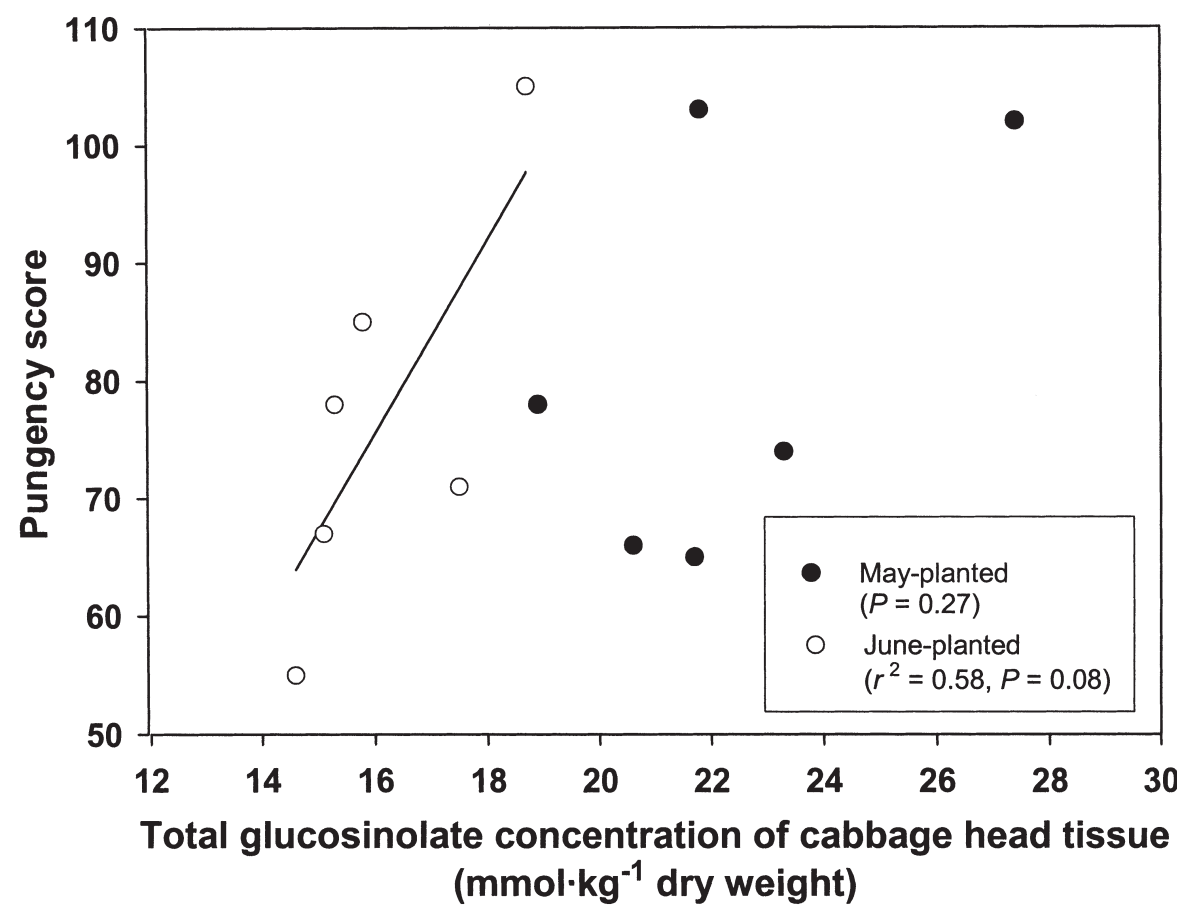

Fig. 3. Relationship between cultivar pungency scores and cultivar mean total glucosinolate concentrations in cabbage planted 10 May and 20 June 2001 at the OARDC North Central Agricultural Research Station in Fremont, Ohio. Data from May- and June-planted plots are presented separately due to differences in panel composition between evaluations.

demonstrating the induction of glucosinolate biosynthesis in Arabidopsis by jasmonic acid (Mikkelsen et al., 2003), a signaling molecule involved in plant defense responses, supports this hypothesis. Additional evidence that the PD effect observed here may have been a response to adverse temperature conditions during head development is provided by MacLeod and Nussbaum (1977) and Rosa et al. (1996), and is supported by the observation that May-planting tended to result in smaller, lighter heads compared to June-planting (Kleinhenz and Wszelaki, 2003; Wszelaki and Kleinhenz, 2003). Also, a trend for higher glucosinolate concentrations in smaller heads within cultivars has been observed (Bible et al., 1980; Van Etten et al., 1976). In controlled environment studies, both supra- and suboptimal temperatures have been shown to increase glucosinolate concentrations in roots, shoots and reproductive tissues of various Brassicacea (Aksouth et al., 2001; Pereira et al., 2002; Rosa and Rodrigues, 1998). However, temperature effects remain incompletely characterized and their potential interaction with soil moisture effects must be considered (Ciska et al., 2000). If the influence of air temperature on glucosinolate concentrations results primarily from greater evapotranspirative demand, then glucosinolate concentrations (and presumably pungency) in fresh cabbage may be minimized via irrigation during periods of high air temperatures, as suggested by Bible et al. (1980), who reported planting date effects on cabbage head thiocyanate concentrations in unirrigated, but not irrigated, plots. Mitigation of low moisture stress via drip irrigation during head development was recently shown to increase cabbage head weight and size and affect flavor (Radovich et al., 2004). Therefore, it is possible that the effects of air temperature on glucosinolate concentrations are not independent of soil moisture. Bible et al. (1980) attributed greater thiocyanate concentrations in June- compared to May-planted cabbage primarily to soil moisture deficits during the entire period of crop development. However, the timing of stress relative to plant-crop development and differences in compounds measured may explain the apparent contrast of their results with those reported here. Soil moisture levels were not recorded in the present study. However, it is reasonable to suspect that, given the similar amount of rainfall and irrigation received by May- and June-planted cabbage in both years (data not shown), soil moisture would have been lower under higher temperatures as a result of greater evapotranspiration. Seasonal differences in daylength, light quality, nutrient availability and pest incidence were not measured in this study, but may also have contributed to the planting date effect observed here (Rosa et al., 1997). However, elucidating the independent and interactive effects of air temperature and soil moisture on cabbage glucosinolate concentrations would contribute significantly to our understanding of the influence of abiotic environmental factors on the glucosinolate system, and our ability to manage it.

The cultivar means for total glucosinolate concentrations reported here generally agree with those reported previously (Ciska et al., 2000; Kushad et al., 1999; Rosa et al., 1996; Van Etten et al., 1976), although differences in analytical methods and reporting units complicate direct comparisons. Sinigrin is a major component of the cabbage glucosinolate profile and the precursor of allyl isothiocyanate, the primary source of pungency in cabbage (Chin et al., 1996; MacLeod, 1976; Yano et al., 1987). Ball et al. (1999) reported a strong $\left(r^{2}=0.95\right)$, positive correlation between total glucosinolate and sinigrin concentrations among 12 cabbage cultivars. This suggests that the cultivars in the current study which differed in total glucosinolate concentrations may also differ in their concentrations of the flavor compound sinigrin. Therefore, it is reasonable to conclude that the relationship between pungency and total glucosinolate levels for June-planted cabbage shown in Fig. 2 is consistent with earlier findings. Glucosinolate concentrations may change in storage (Rosa et al., 1997). However these changes are expected to be minimal and uniform across treatments under the storage conditions employed in the study (Ball et al., 1999, Radovich et al., 2004). However, if changes occurred, they may have contributed to a reduction in fit between glucosinolate and pungency values. Differences in storage time ( $20 \mathrm{~d}$ ) among cultivars may have contributed additional variability in sensory scores. However, Ball et al. (1999) reported no significant change in glucosinolate concentrations or pungency over a period of $60 \mathrm{~d}$ in cabbage heads stored at $1{ }^{\circ} \mathrm{C}$ and $90 \%$ relative humidity. Although our storage conditions differed slightly from Ball et al. (1999), we expect that minimal variability was introduced due to differences in storage time, and that any such variability would affect the fit but not direction of the relationship in Fig. 3. Differences in panel composition, perhaps combined with much higher levels of total glucosinolates leading to panelist fatigue, may have also contributed to the lack of a significant relationship in May-planted cabbage.

Data reported here demonstrate that the planting date effect was consistent across the cultivars studied. Although few in number, the genotypes employed in this study are commercially important in the U.S. Higher glucosinolate concentrations in May-planted cabbage was attributed to the greater incidence of supraoptimal temperatures during head development in May- than June-planted cabbage. The data suggest that $\mathrm{PD}$ and $\mathrm{C}$ may act independently in influencing total glucosinolate concentrations in commercially available cabbage. Likewise, the data underscore the need to describe potential soil moisture effects (and their interaction with temperature) on crop glucosinolate concentrations. Doing so will improve our understanding of the influence of abiotic environmental factors on the glucosinolate system and the ability to manage it for grower and consumer benefit.

\section{Literature Cited}

Aksouth, N.M., B.C. Jacobs, F.L. Stoddard, and R.J. Mailer. 2001. Response of canola to different heat stresses. Austral. J. Agr. Res. 52:817-824.

Ball, S., L. Skog, R. B. Smith, D. Murr, and A. McKeown. 1999. Reducing pungency in commercial coleslaw by controlling glucosinolate concentrations. Dept. Plant Agr., Univ. Guelph, Ont., Proj. Rpt. 648.

Bible, B.B., H.Y. Ju, and C. Chong. 1980. Influence 
of cultivar, season, irrigation, and date of planting on thiocyanate ion content in cabbages. J. Amer. Soc. Hort. Sci. 105:88-91.

Bones, A.M. and J.T. Rossiter. 1996. The myrosinase-glucosinolate system, its organization and biochemistry. Physiol. Plant. 97:194-208.

Chen, S. and E. Andreasson. 2001. Update on glucosinolate metabolism and transport. Plant Physiol. Biochem. 39:743-758.

Chen, S. and B.A. Halkier. 2000. Characterization of glucosinolate uptake by leaf protoplasts of Brassica napus. J. Biol. Chem. 275:22955-22960.

Chin, H.W., Q. Zeng, and R.C. Lindsay. 1996. Occurrence and flavor properties of sinigrin hydrolysis products in fresh cabbage. J. Food Sci. 6:101-104.

Ciska, E., B. Martyniak-Przybyszewska, and H. Kozlowska. 2000. Content of glucosinolates in Cruciferous vegetables grown at the same site for two years under different climatic conditions. J. Agr. Food Chem. 48:2862-2867.

Fahey, J.W., A.T. Zalcmann, and P. Talalay. 2001. The chemical diversity and distribution of glucosinolates and isothiocyanates among plants. Phytochem. 56:5-51.

Fahey, J.W., Y. Zhang, and P. Talalay. 1997. Broccoli sprouts: An exceptionally rich source of inducers of enzymes that protect against chemical carcinogens. Proc. Natl. Acad. Sci. USA 94:10367-10372.

Heaney, R.K. and G.R. Fenwick. 1981. A micro-column method for the rapid determination of total glucosinolate content of Cruciferous material. Z. Pflanzenzuchtg 87:89-95.

Kleinhenz, M.D. and A. Wszelaki. 2003. Yield and relationships among head traits in cabbage (Brassica oleracea, L. Capitata Group) as influenced by planting date and cultivar I. Fresh market. HortScience 38:1349-1354.

Kushad, M.M., A.F. Brown, A.C. Kurilich, J.A. Juvik, B.P. Klein, M.A. Wallig, and E.H. Jeffery. 1999. Variation of glucosinolates in vegetable crops of Brassica oleracea. J. Agr. Food Chem. 47:1541-1548.

MacLeod, A.J. 1976. Volatile flavor components of the Cruciferae, p. 307-330. In: J.G. Vaughn, A.J.
MacLeod, and B.M.G. Jones (eds.). The biology and chemistry of the Cruciferae. Academic Press, London.

MacLeod, A.J and M.L. Nussbaum. 1977. The effect of different horticultural practices on the chemical flavor composition of some cabbage cultivars. Phytochemistry 16:861-865.

Mikkelsen, M.D., B.L. Petersen, E. Glawischnig, A.B. Jensen, E. Andreasson, and B.A. Halkier. 2003. Modulation of CYP79 genes and glucosinolate profiles in Arabidopsis by defense signalling pathways. Plant Physiol. 131:298-308.

Pereira, F.M.V., E. Rosa, J.W. Fahey, K.K. Stphenson, R. Carvalho, and A. Aires. 2002. Influence of temperature and ontogeny on the levels of glucosinolates in Broccoli (Brassica oleracea Var. italica) sprouts and their effect on the induction of mammalian phase 2 enzymes. J. Agr. Food Chem. 50:6239-6244.

Radovich, T.J.K., M.D. Kleinhenz, A. SanchezVela, J.C. Scheerens, and B. Schult. 2003. Fresh cabbage sensory quality: Components and the impact of production factors. Acta Hort. 628:787-795.

Radovich, T.J.K., M.D. Kleinhenz, J.F. Delwiche, and R.E. Liggett. 2004. Triangle tests indicate that irrigation timing affects fresh cabbage sensory quality. Food Qual. Preference 15:471-476

Radovich, T.J.K., M.D. Kleinhenz, and N.J. Honeck. 2004. Important cabbage head traits at five points in development. J. Veg. Crop Prod. (in press).

Rask, L., E. Andreasson, B. Ekborn, S. Eriksson, B. Pontopiddan, and J. Meijer. 2000. Myrosinase: gene family evolution and herbivore defense in Brassicacae. Plant Mol. Biol. 42:93-113.

Rosa, E.A.S., R.K. Heaney, C.A.M. Portas, and G.R. Fenwick. 1996. Changes in glucosinolate concentrations in Brassica crops (B. oleracea and $B$. napus) throughout growing seasons. J. Sci. Food Agr. 71:237-244.

Rosa, E.A.S., R.K. Heaney, G.R. Fenwick, and C.A.M. Portas. 1997. Glucosinolates in crop plants. Hort. Rev. 19:99-215.

Rosa, E.A.S. and P.M.F. Rodrigues. 1998. The effect of light and temperature on glucosinolate concentration in the leaves and roots of cabbage seedlings. J. Sci. Food Agr. 78:208-211.

Rubatzky.V.E. and M. Yamaguchi. 1997. Cole crops, p. 371-415. In: World vegetables. Chapman and Hall, New York.

Siemens, D.H. and T. Mitchell-Olds. 1996. Glucosinolates and herbivory by specialists (Coleoptera: Chrysomelidae, Lepidoptera: Plutellidae): consequences of concentration and induced resistance. Environ. Entomol. 25:1344-1353.

The Ohio State University. 2003. The OARDC weather system. Ohio Agr. Res. Dev. Ctr. Wooster. 28 July 2003. <http://www.oardc. ohio-state.edu/centernet/htm $>$.

Van Doorn, H.E., G.C. van der Kruk, G.J. van Holst, N.C.M.E. Raaijmakers-Ruijs, E. Postma, B. Groeneweg, and W.H.F. Jongen. 1998. The glucosinolates sinigrin and progoitrin are important determinants for taste preference and bitterness of Brussels sprouts. J. Sci. Food Agr. 78:30-38.

Van Etten, C.H., M.E. Daxenichler, P.H. Williams, and W.F. Kwolek. 1976. Glucosinolates and derived products in cruciferous vegetables. Analysis of the edible part of twenty-two varieties of cabbage. J. Agr. Food Chem. 24:452-455.

Van Etten, C.H., M.E. Daxenichler, H.L.. Tookey, W.F. Kwolek, P.H.Williams, and O.C. Yoder. 1980. Glucosinolates: Potential toxicants in cabbage cultivars. J. Amer. Soc. Hort. Sci. 105:710-714.

Verhoeven, D.T.H., H. Verhagen, R.A. Goldbohm, P.A. van den Brant, and G. van Poppel. 1997. A review of mechanisms underlying anticarcinogenicity by Brassica vegetables. ChemicoBiological Interactions 103:79-129.

Wszelaki, A. and M.D. Kleinhenz. 2003. Yield and relationships among head traits in cabbage (Brassica oleracea, L. Capitata Group) as influenced by planting date and cultivar II. Processing. HortScience 38:1355-1359.

Yano, M, H. Itoh, and R. Saijo. 1987. Allyl isothiocyanate and its contribution to pungency in cabbage. J. Food Sci. Technol. (Japan) 34:608-611. 